\title{
Expanding the design space through innovative design and manufacturing processes
}

\author{
F. B. Prinz \\ Stanford University, Building 530, 440 Escondido Mall, \\ Stanford, CA., 94305-3030, USA \\ Phone:650-723-0084, Fax:650-723-5034 \\ E-mail:fbp@cdr.stanford.edu
}

\begin{abstract}
The subject of design and manufacturing has received increasing attention in practically all industrialised countries. Ever increasing competition has forced most manufacturing organisations to rethink the process by which they create new products and improve existing ones. The following paper attempts to describe the traditional product evolution cycle by reviewing historic as well as modern methods of product design and manufacturing. Several limitations and constraints in the traditional process are identified and related to innovative methods under development at Carnegie Mellon's Engineering Design Research Center and at Stanford's Rapid Prototyping Laboratory.
\end{abstract}

\section{Keywords}

Manufacturing, design, process, product, new technologies, layout design 


\section{THE PRODUCT EVOLUTION CYCLE}

Understanding what needs to be done to position our manufacturing companies in the global market race can best be accomplished by considering the entire product evolution cycle, starting from customer perception or a technical opportunity and continuing all the way down to product disposal and recycling. The goals are obvious: systems, methodologies, and tools are needed which help produce better products faster. To define the requirements for some of these, let us consider the information flow between various stages of product evolution. Two key information flows occur during the creation of a product. The first is synthesis (Figure 1).

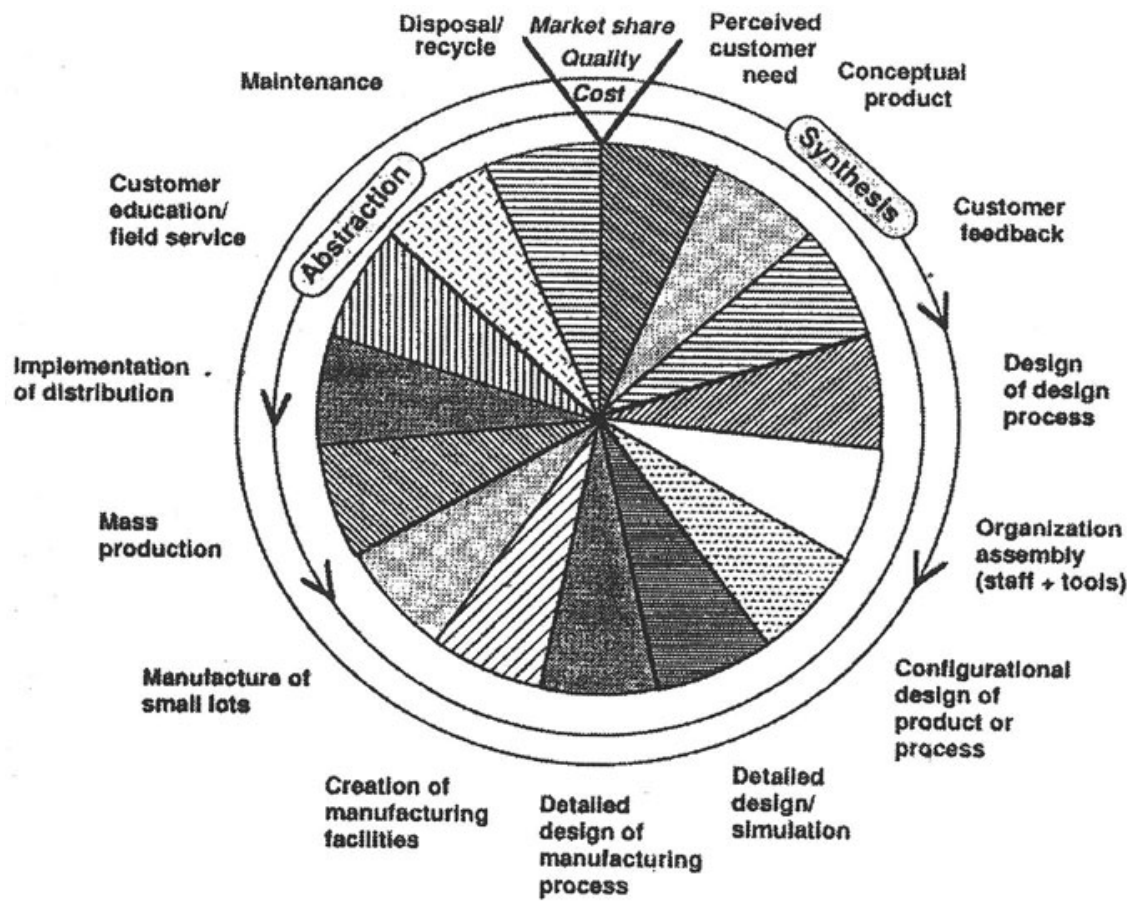

The product cycle

Figure 1: The product life-cycle.

It focuses on the downward information flow in the product cycle. At any stage of the product development there is a large number of alternatives from which to choose. The role of synthesis is the systematic creation of alternatives as the 
product design and the design process become increasingly more specific. On the other hand, downstream concerns, such as performance and manufacturability, frequently determine constraints on possible alternatives. These constraints need to be accessible at any stage of the product creation cycle where they may influence the process of synthesis. This second information flow represents an abstraction process, since very detailed downstream information usually needs to be presented upstream in a less detailed fashion. A key factor in determining the responsiveness, productivity, and quality of a manufacturing organisation is the degree to which these information flows are integrated into the corporate structure.

A concrete example of information flow in an industrial setting: Imagine a car design team synthesising a new car body. The current manufacturing approach is to spot-weld several hundred pieces of sheet metal together. An attractive alternative is an assembly of lightweight aluminium beams on which plastic panels are mounted. This design is called a "space frame". A design group confronted with this decision needs to understand the essence of aluminium casting and extrusion in order to make an intelligent decision about whether the alternative design is feasible or not. This means simplifying the details of the process to the extent that a non-expert can take this information as the basis for directing the design one way or the other. The faster and more efficiently the manufacturing process constraints are presented to the designer, the faster and more efficiently they will be able to synthesise a new product.

Decision-support methodologies and tools, which aid in synthesising and finding constraints early on in the manufacturing process, are key in improving the quality and speed of product creation. Researchers around the world in industry and academia have joined in creating the next generation of tools and methods. It is well known that advances in computer science and communications are pivotal in the development of such decision aids.

The following touches upon only a few of these ideas, tools, and methods. In particular, focus will be placed on that part of the product creation cycle in which a detailed design is reviewed and critiqued by a "decision support system" which has knowledge about certain manufacturing constraints. Consider designing a license plate holder, a relatively simple component for a car (Figures 2,3).

One side of this license plate holder has strengthening ribs to increase the bending strength of the component. On the other side of the same component, you would discover that there is an unevenness in the surface structure, which by design was supposed to be perfectly flat. The reason for this flaw is that the designer who chose the dimensions of the strengthening rib did not apply good design practice and caused the build-up of a volume concentration underneath the strengthening rib (Figure 4). 


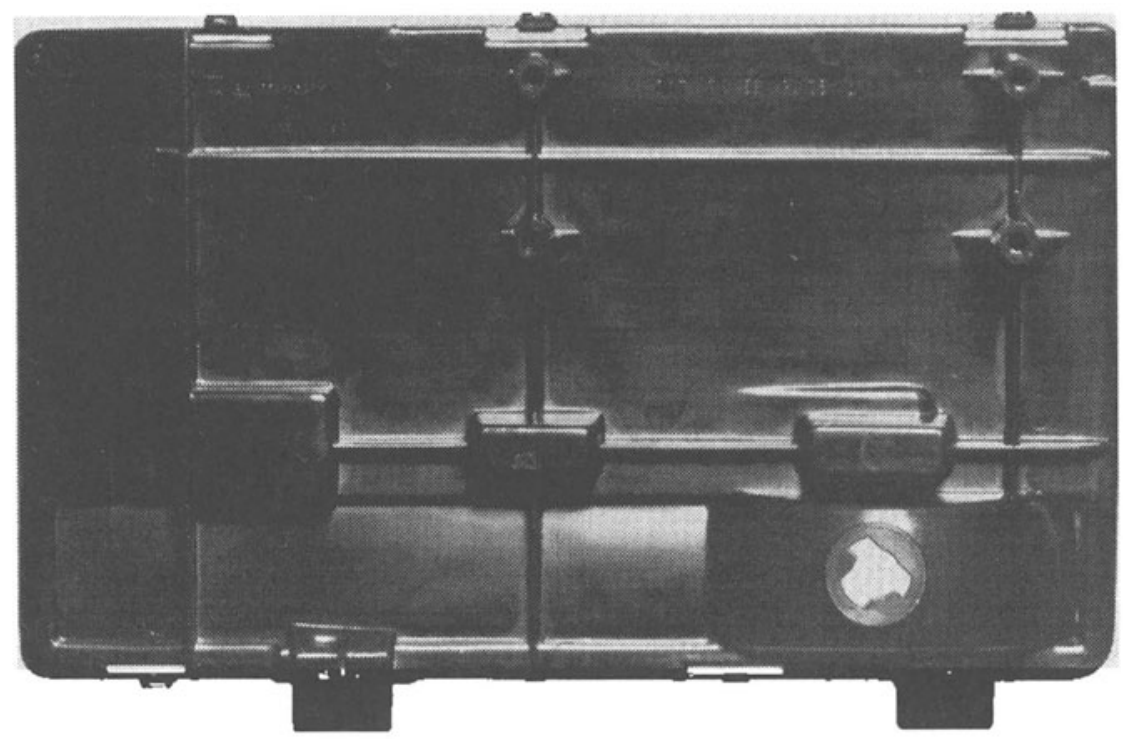

Figure 2: A license plate holder of a car.

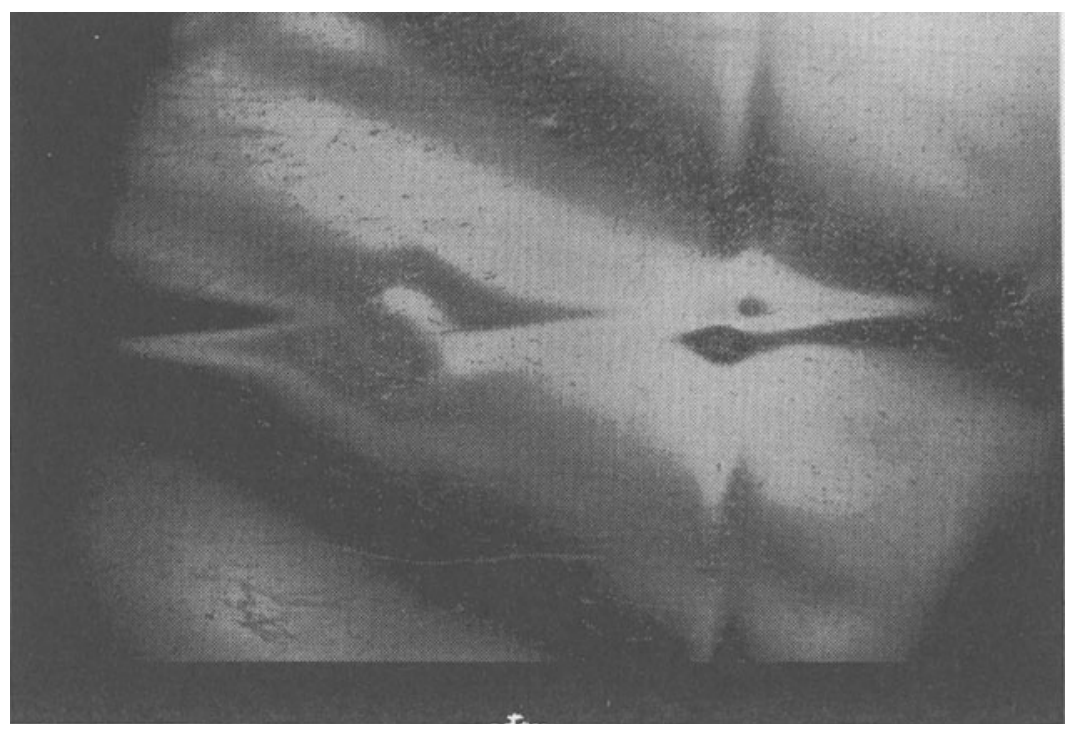

Figure 3: Part of a license plate holder. 
Had some "expert" or some system warned the designer, a mistake which cost tens of thousands of dollars in losses because the mould for the part had to be rebuilt could have been avoided. Even worse, a couple of months in the product creation cycle were lost. An expert system working together with the CAD/CAM system which does precisely that can be viewed in (Figure 5) (Hall et al., 1990).

This system recognised certain geometric features which are important from a manufacturing viewpoint. Within that system, the designer receives feedback about whether the dimensions he has chosen are compatible with good manufacturing practice. Decision support tools such as this can significantly reduce errors, cost, and development time. However, the question which still needs to be asked is: Once we have achieved all that, are we going to be better off? Well, certainly we will be at least somewhat better off, because it will take fewer iteration cycles to develop a product, and that will obviously strengthen the market position of companies employing such tools.

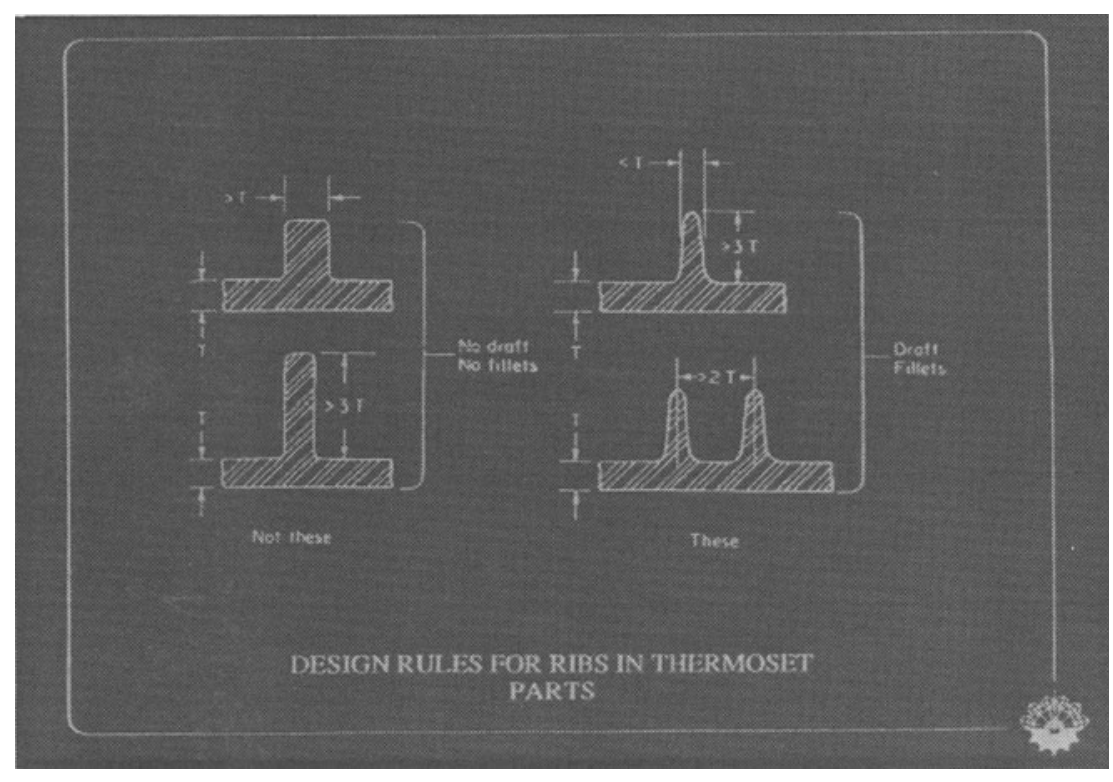

Figure 4: Volume concentrations caused by design.

From a different perspective, however, if we keep on working over the next few years simply building more and more design critiques, we will consequently have a number of similar systems which prevent designers from making mistakes by informing them of manufacturing constraints. Furthermore, we will be locking 
ourselves into constraints on manufacturing processes rather than trying to remove those limitations.

\section{Design Critique}

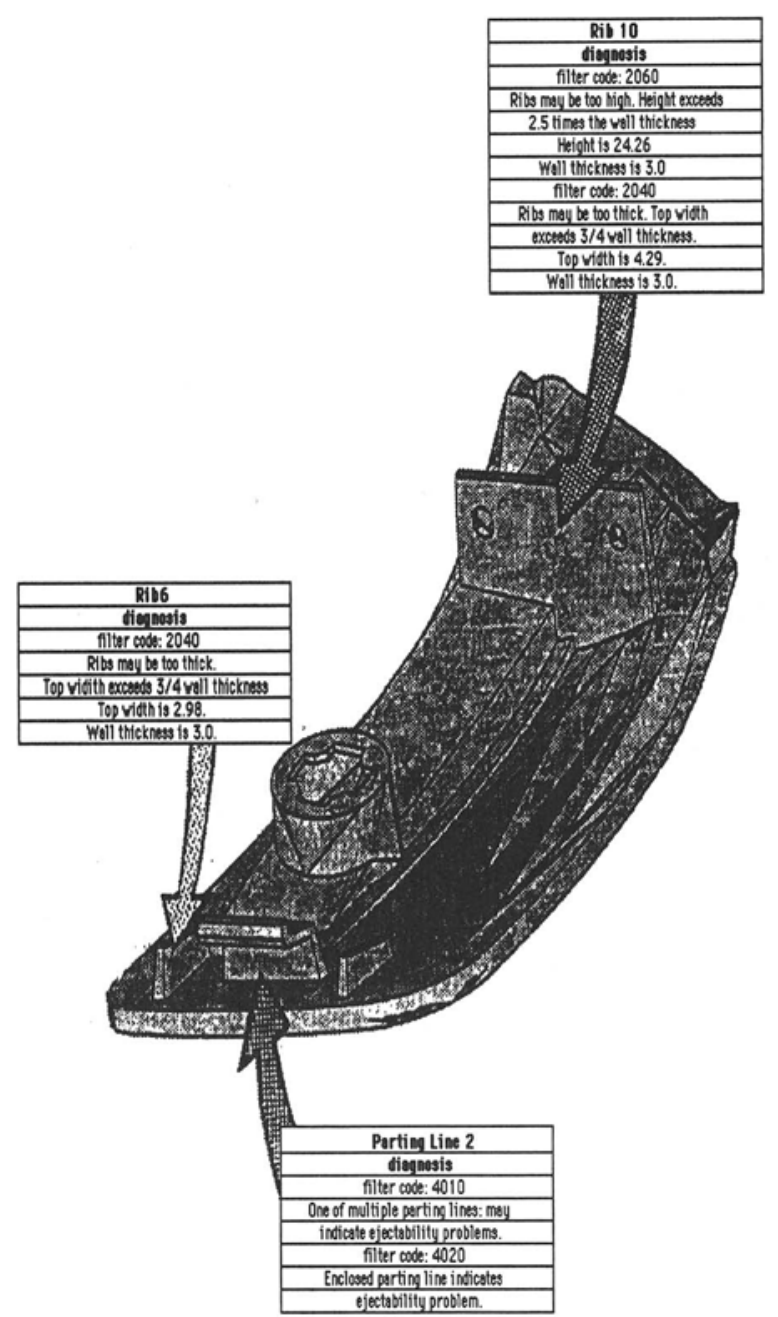

Figure 5: A CAD/CAM system working together with an expert system. 
Preserving existing knowledge may lock us into a certain paradigm which may become increasingly difficult to alter. So, rather than streamlining and automating, let's first look at how we have been making things. Maybe there are techniques which can remove existing process constraints, such as opening up the design space, and allow the creation of products we could have never dreamed of before.

\section{TRADITIONAL MANUFACTURING METHODS: WHAT THEY TEACH US}

To better understand how things are made today it's always useful to look in to the past. History shows that in manufacturing the components of a product are first formed in one step and then assembled in another. Although the ways of forming a product and the means of assembling it have changed, the basic sequence of forming parts first and then assembling them has always remained. Three historical examples are given to illustrate this sequence and also show how forming and assembly have changed through time. The examples chosen are 1) the creation of an antler spearhead dating back 12,000 to 8,000 years, 2) the making of a common three-legged stool from 15th-century Europe, and 3) Henry Ford's revolutionary use of the assembly line in automobile production. These examples, which illustrate traditional methods of product creation, will then be compared with new ideas and technologies which are currently in a research or pre-competitive stage.

\section{I Prehistoric antler spearhead and stone tools}

The working of bone or antler tools reached a highpoint during the period from 12,000 to 8,000 years before our era. Finely crafted javelins, sewing needles, and harpoons were formed from animal bones, tusks, or antler. Equally impressive are the stone tools used in the formation of these utensils.

The first example, a spearhead made from antler material, was formed with the aid of stone gravers and scrapers. The craftsman first select a slightly curved antler shaft of a male reindeer, killed during the season when the material was most dense. The form of the spear was then cut from the antler with deep incisions made with the graver (Figure 6) (Daumas, 1969).

This rough "cut" or piece was trued and filed down with a scraper. Following this finishing process, the spearhead was aligned with the aid of shaft-straightener," which contained a pierced hole and was also made from reindeer antler. 


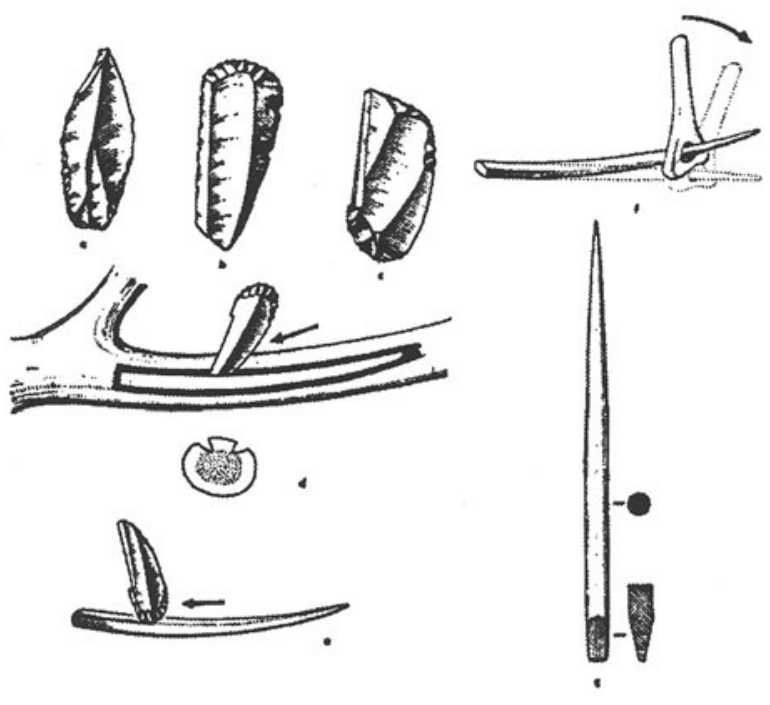

Forming a prehistoric antler spearhead.

Figure 6: Prehistoric forming.

One can assume that the completed spearhead was mounted on a thin cylindrical shaft of wood in the assembly stage.

The stone tools used by prehistoric craftsman to fashion the bone or antler implements also represent a high level of technical skill. Early man's knowledge of stone covered a range of materials, such as flint and obsidian on the one hand and coarse-grained granites on the other. The craftsman acquired through tradition a well-developed feeling for these materials, which included knowledge of inherent lines of weakness and faults in stones and how the force of a blow may be distributed. His fine manual and perceptual skills enabled him to strike a stone to achieve a desired shape.

At first, only the simplest hammer-stone method of shaping was used. This involved using a water-worn pebble as a hammer to chip off a flake from another stone (Figure 7)

To do this, a tool maker had to know the correct angle of striking the stone to remove a flake at the right point and in the desired direction. Through experience he learned that the angle between his blow and the direction in which he wanted to remove the flake had to be roughly 120 degrees. This "first-cut" flake could then be further worked into a suitable tool. 


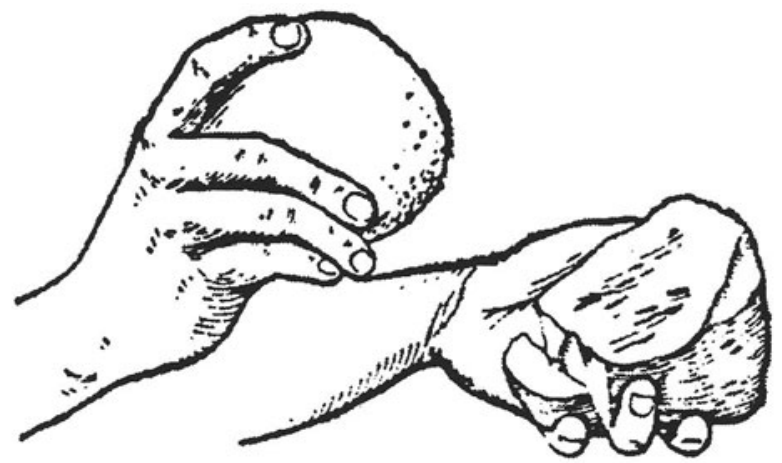

Figure 7: Using a hammer-stone to chip off a rough-cut flake.
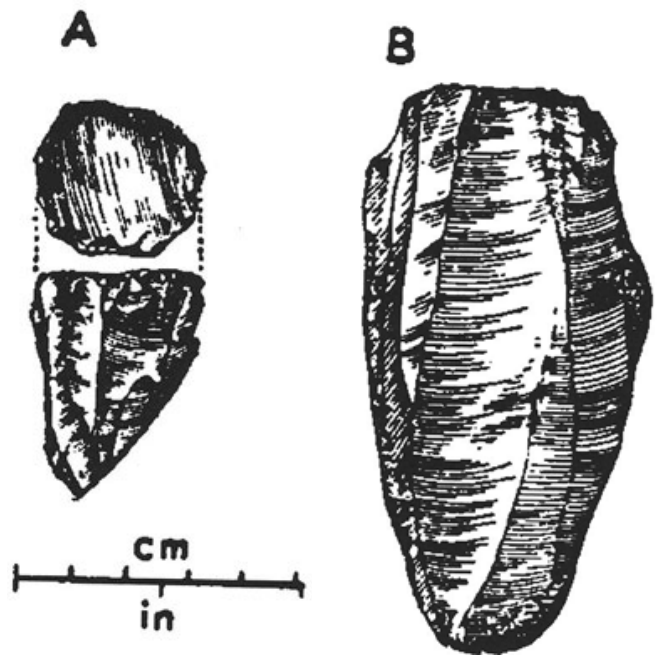

C

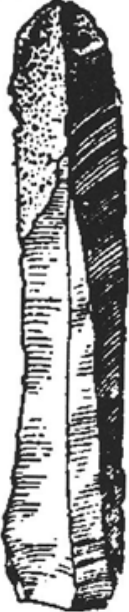

Figure 8: Stone cores (A, B) with semi-finished blade (C). 
By approximately 13,000 B.C., prehistoric man was preparing carefully trimmed stone cores from which long, narrow blade flakes with parallel edges could be struck off quickly (Figure 8) (Kranzberg Pursell, 1967).

These semi-finished blades could then be made into scrapers or gravers by secondary trimming. By 7,000 B.C., these techniques of working in both bone and stone resulted in composite tools such as this arrowhead in which small flints were mounted with pitch in a shaft of bone.

\subsection{Turned furniture of the middle ages}

Another example of forming and assembly is the making of turned furniture in the 10 th through the 15th centuries, a period of time which marked the highest level of medieval civilisation. Two separate crafts were involved in furniture making at this time--the joiners and the turners. The joiners appeared on the scene in the 11th and 12th centuries. Their skill focused on the shaping and fitting together of the component parts of a piece of furniture. The turners, on the other hand, were the oldest craft of furniture makers. They practiced their trade as early as the 8th century B.C. in the Near East, and they made furniture throughout northern Europe from Roman times. Their craft was based on the use of the lathe to cut a furniture part as it rotated or turned on its axis. A simple three-legged stool made around 1430 is an excellent example of forming and assembly, and the advance of the skills and tools at this time. The posts and spindles of the stool were turned on a pole and treadle lathe (Figure 9).

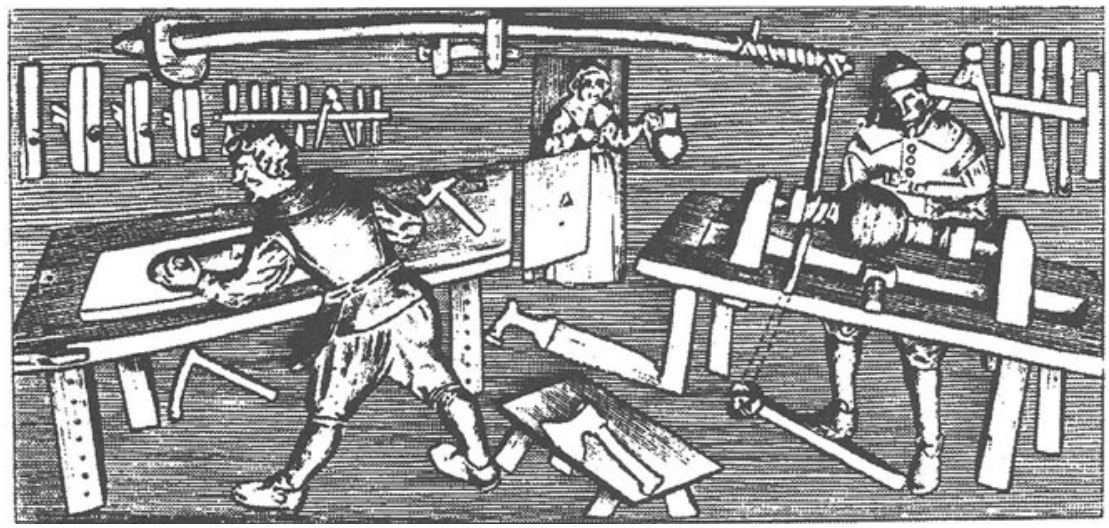

Figure 9: A joiner and turner at work c 1600. 
The furniture part was held between two centres and rotated by means of a cord wrapped around it. The turner controlled the speed of turning through the use of a foot treadle and fixed pole. When the turner stepped down on the treadle with one foot, the piece was rotated rapidly in one direction. When his foot was lifted, the elasticity of the pole pulled back the cord, rotating the part in the opposite direction.

The assembly of the three-legged stool was done with dowelled joints. The seat of the chair was supported by three heavy turned posts, which were held in place with a configuration of spindles. Judging by their appearance in medieval pictures, these chairs must have been produced in great numbers.

\subsection{Assembly line in automobile production}

The final example of the forming and assembly steps in manufacturing is the contribution made by Henry Ford. The assembly line, which he refined and used on a large scale, embodied the vitality and efficiency of American mass production.

Ford borrowed the concept of continuous movement from the Cincinnati and Chicago meat packing industries who pioneered it in the 1870s. To increase productivity, they hung carcasses on monorail trolleys and transported them past workers in a steady pace with powered movement. Production increased because the pace of work was timed, jobs were specialised, and unnecessary movement by the worker and the product was minimised. Ford caught the idea and introduced it into the production of his Model $\mathrm{T}$ with impressive results.

The assembly of flywheel magnetos was the first step. On May 1, 1913 the moving line for their assembly was installed. At first, the magnetos were pushed on rails from one work station to the next (Figure 10) (Singer et a). Assembly time dropped from 20 minutes to 13; when powered movement was added, the time dropped to five minutes.

Ford's success with the magneto line led him to apply it to chassis and motor assembly. The average time for the assembly of a chassis, using stationary work stations for each chassis, was 12.5 hours. In a crude trial, Ford attached a chassis to a rope and windlass and pulled it 250 feet past bins of parts. Six assemblers moved with the chassis adding parts along the way. Assembly time was reduced to six hours. Refinements included a chain drive, stationary locations for assemblers, and optimum heights for work stations and parts-supply to reduce worker movement. With these improvements, assembly time was reduced to 93 minutes. Equally impressive times resulted when continuous movement was applied to motor assembly. 


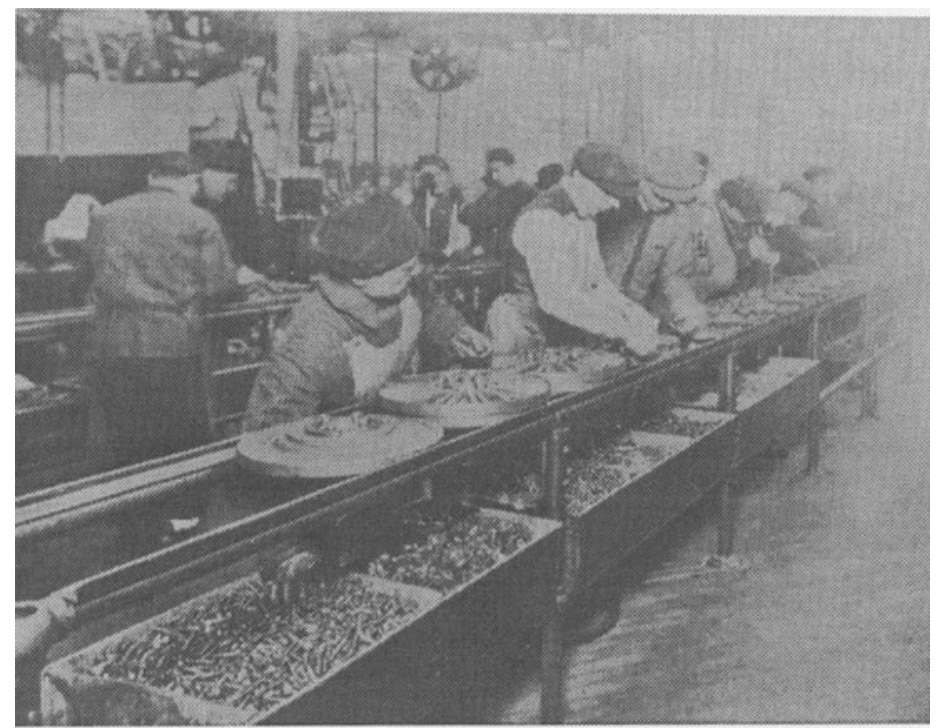

Figure 10: Assembling flywheel magnetos at the Ford Motor Company.

It wasn't until the mid-1930s that continuous movement could be extended to the assembly of the automobile body. Before 1935, the body was a wooden frame on which steel sheets were attached (Figure I 1) (Hindle and Lubar, 1986). Building it was slow and costly, and not conducive to assembly line techniques (Figure 12) (Hindle and Lubar, 1986).

The change to an all-metal body allowed manufacturers to form such parts as the hood, fenders, or roof, in presses and then weld them together on the assembly line (Figure 13) (Hindle and Lubar, 1986).

This final link in the automobile assembly line was achieved when the steel industry responded by developing the cold reduction process to produce steel sheets. Steel rolled and annealed in this way could now meet the tremendous stresses of stamping and retain a smooth surface when formed in the presses.

The assembly line, embodying the principle of continuous motion, sped through the automobile industry and other mass production metal-working industries. In effect, it set off a wave of new exploration into ways of achieving productivity gains and set the pace for American manufacturing in the coming decades. 


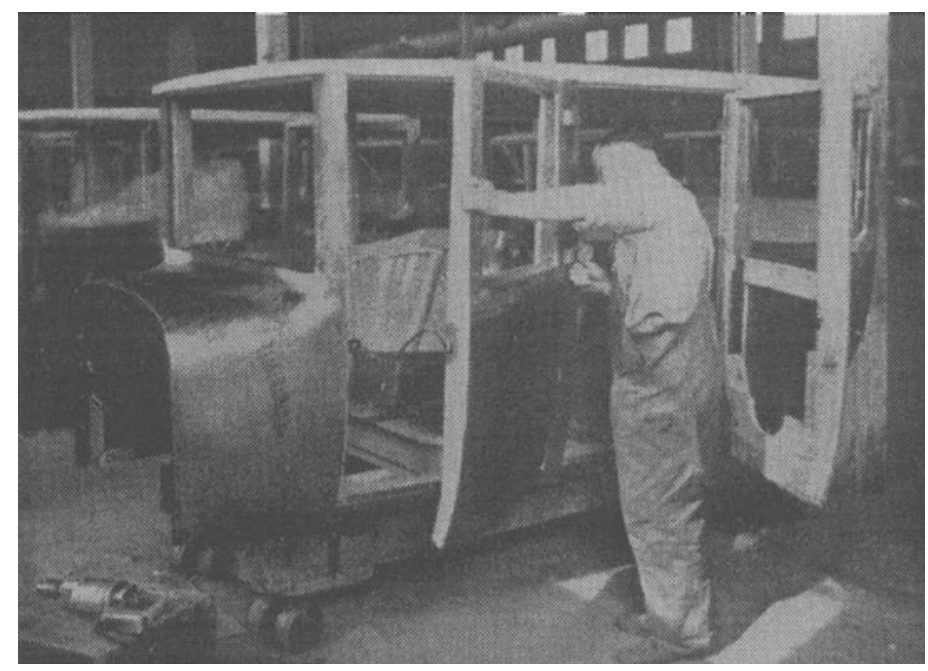

Figure 11: Attaching steel sheets to a wooden auto body prior to 1935 .

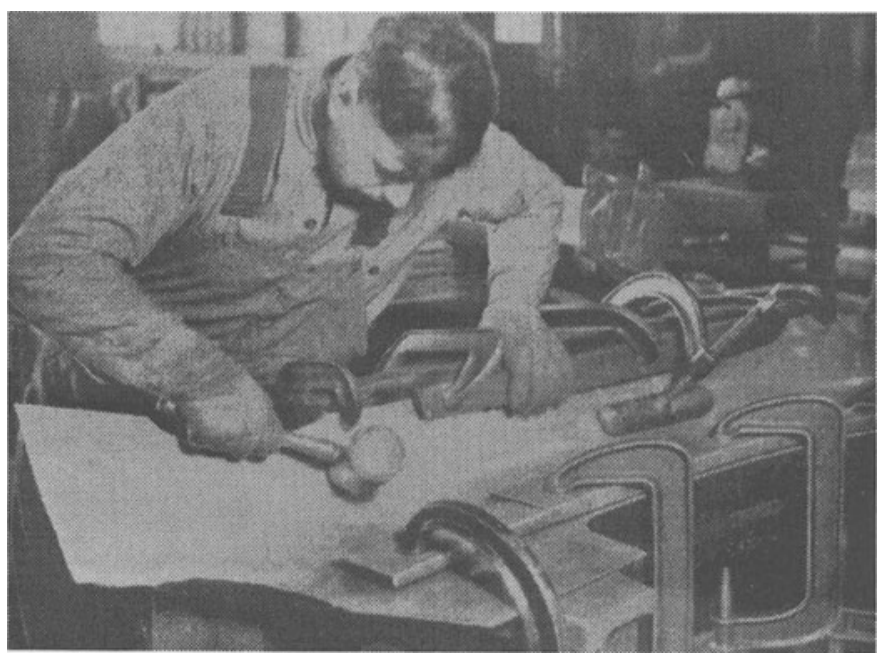

Figure 12: Forming automobile body parts by hand. 


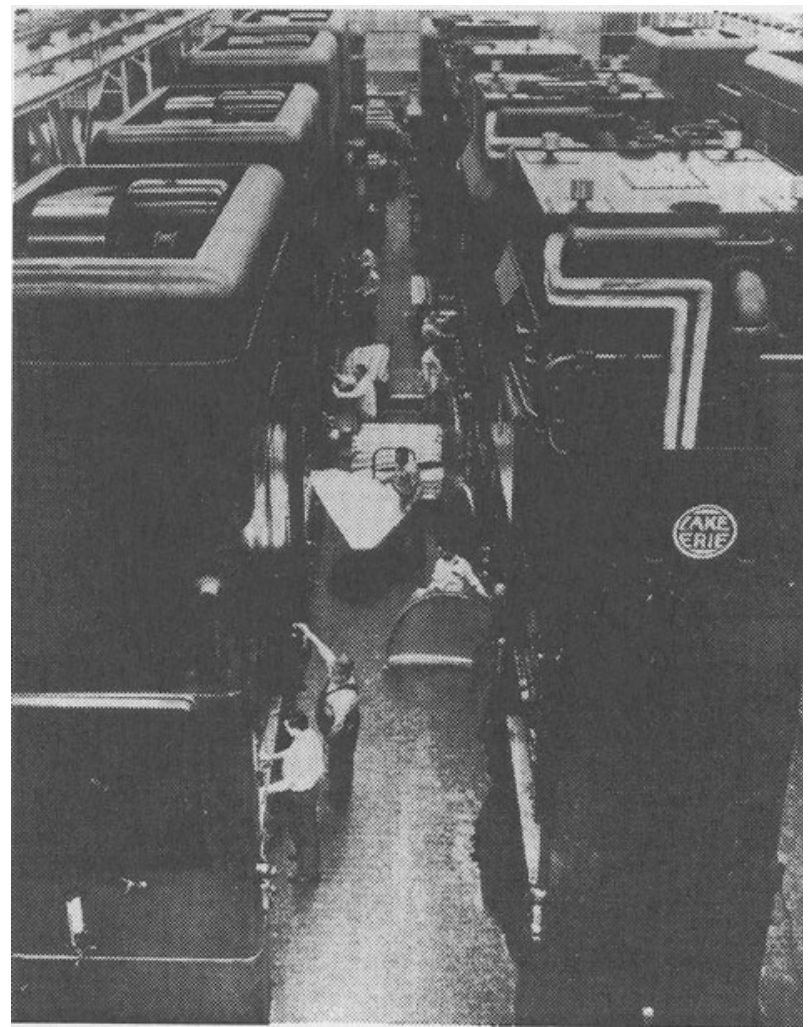

Figure 13: A giant stamping press for forming automobile body parts.

\subsection{Historical conclusions}

Some important themes show up in three historical examples of forming and assembling that have been presented.

1) The number of people needed to manufacture a product has increased dramatically. As a result, a division of tasks was instituted. Design and manufacturing, once the domain of one person making a spearhead, were delegated to separate groups in the production of the Model T.

2) The workplace has become larger. In the medieval workshop, the joiner and turner could resolve manufacturing problems on the spot. In the large corporation, communication would prove more difficult.

3) New concepts have been responsible for decreasing production times and controlling output. The carefully prepared stone core resulted in uniform blade 
flakes that could be quickly produced. Interchangeable parts led to a division of labour and to task-specific machinery that reduced the time to produce a standardised part. Continuous motion of the assembly line speeded up automobile production and permitted its mass production.

These trends have continued into the present, but in each case formation of the components of a product preceded its assembly. Today, we are discovering that this traditional method of forming first and assembling later is making it difficult to manufacture certain products. Imagine the creation of products like "smart structures", components which feel stress, temperature, or which have embedded actuators. While not impossible, the manufacture of such products with conventional manufacturing is difficult where one makes individual components first and subsequently puts them together.

\section{NEW MANUFACTURING TECHNOLOGIES: A BREAK WITH THE PAST}

Let us look at alternate manufacturing technologies which do not impose the well known limitations; technologies where we can shape the components and assemble them simultaneously. And rather than shaping objects through material removal or reshaping, let's consider methodologies in which we incrementally add the material by some deposition process. Technique like thermal spraying are candidate processes. History has shown us that the introduction of new concepts results in very significant advances in manufacturing. Prehistoric man's use of carefully prepared stone cores allowed him to produce uniform semi-finished tools. More recently, Henry Ford's application of the assembly line permitted the mass production of the automobile.

\subsection{Thermal spraying}

Thermal spraying can be used for any material melts. One can deposit layers as thin as a few microns, but also as thick as couple of inches.

The capability of depositing materials in any desirable manner see very attractive. We may be able to manufacture materials with unique properties, properties which can be designed up-front and which meet certain functional requirements. For example, a component could be manufactured which is hard on one side but tough on the other, or which contains "smarts" the sense of having the ability to feel and possibly to act. The making of such component is obviously not a trivial task.

Net-shape fabrication processes can be classified into three categories according to material removal, material reshaping, and material deposition processing. For example, conventional machining processes build shapes removing material from 
bulk stock, while casting processes reshape molten material into the desired solidified forms. While deposition processes relatively new. Currently applied shape deposition processes build parts $b$ incremental material build-up of thin 2$1 / 2$ dimensional layers. A broad class these processes builds with planar crosssections, and the growing structure is supported by complementary shaped sacrificial layers (Figure 14).

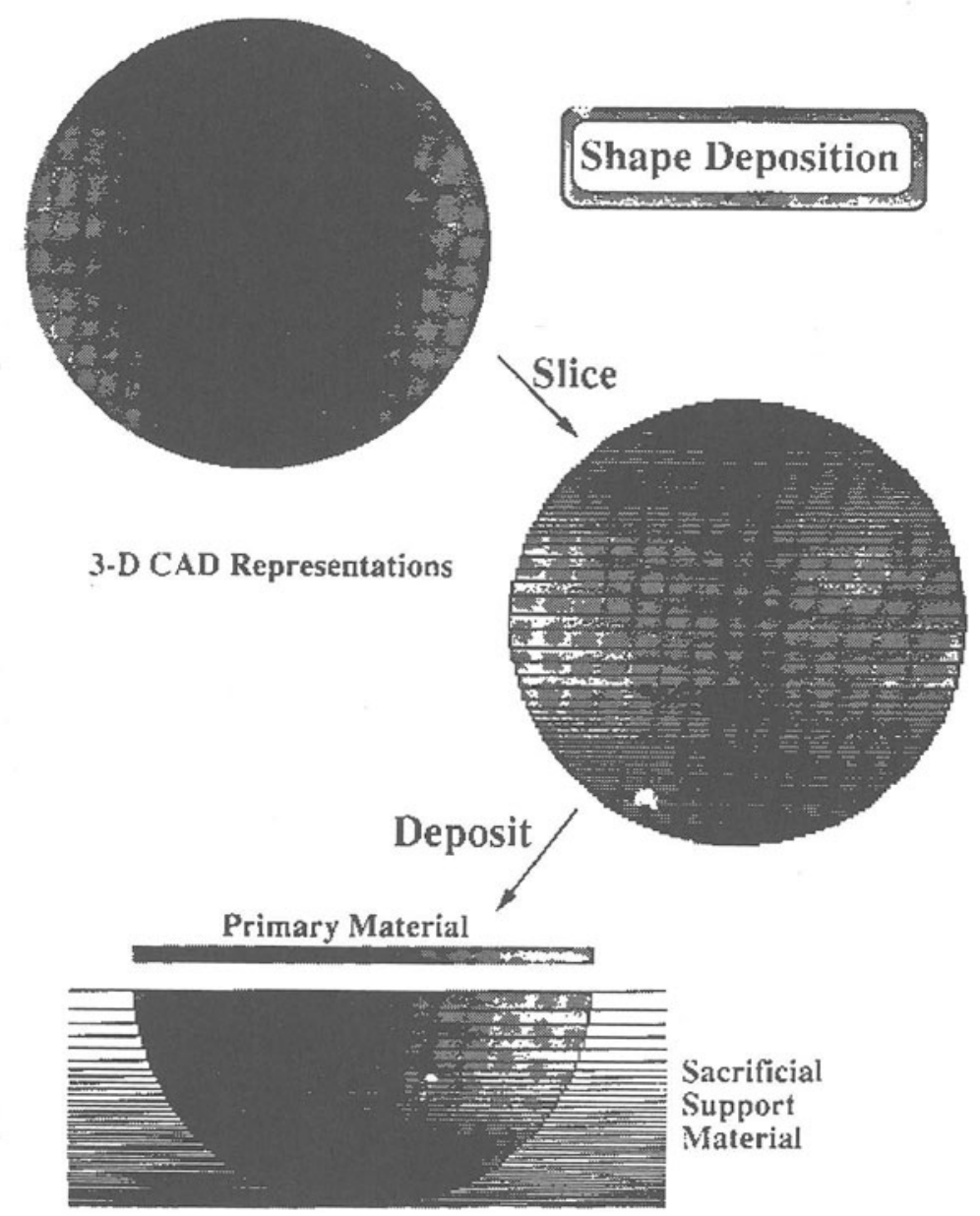

Figure 14: Shaping sacrificial layers. 
The cross-sectional descriptions are generated by "slicing" three dimensional computer representations into "slices" which may vary in thickness. Several alternative deposition materials and deposition processes arc available for building the object, including selective laser sintering, three-dimensional printing, layered object manufacturing, and Cubital's "Solider". The later is similar to 3-D Systems Stereo-lithography in that both are based upon photo-polymerisation processes. Stereo-lithography, however, requires explicit support structure design.

To further illustrate the concept of layered manufacturing and its potential impact for design and manufacturing we focus on an experimental technique called Shape Deposition Manufacturing (SDM).

\subsection{SDM process overview}

Shape Deposition Manufacturing (SDM) (Merz et al., 1994) is a solid freeform fabrication (SFF) methodology which is currently being developed at Stanford University and Carnegie Mellon University. SDM (see Figure 15) systematically combines the advantages of material additive, layered manufacturing processes (i.e., relative ease of planning, complex shapes, functional material gradients) with the benefits of more traditional material removal processes, such as the precision of CNC machining, and the high quality of proven material deposition processes, such as welding. In addition, discrete components, such as sensors, can be embedded within SDM structures as they are built up.

The combination of all of these capabilities enables the creation of unique, highperformance, multi-material, embedded structures from next-generation tooling to rugged underwater computers. 


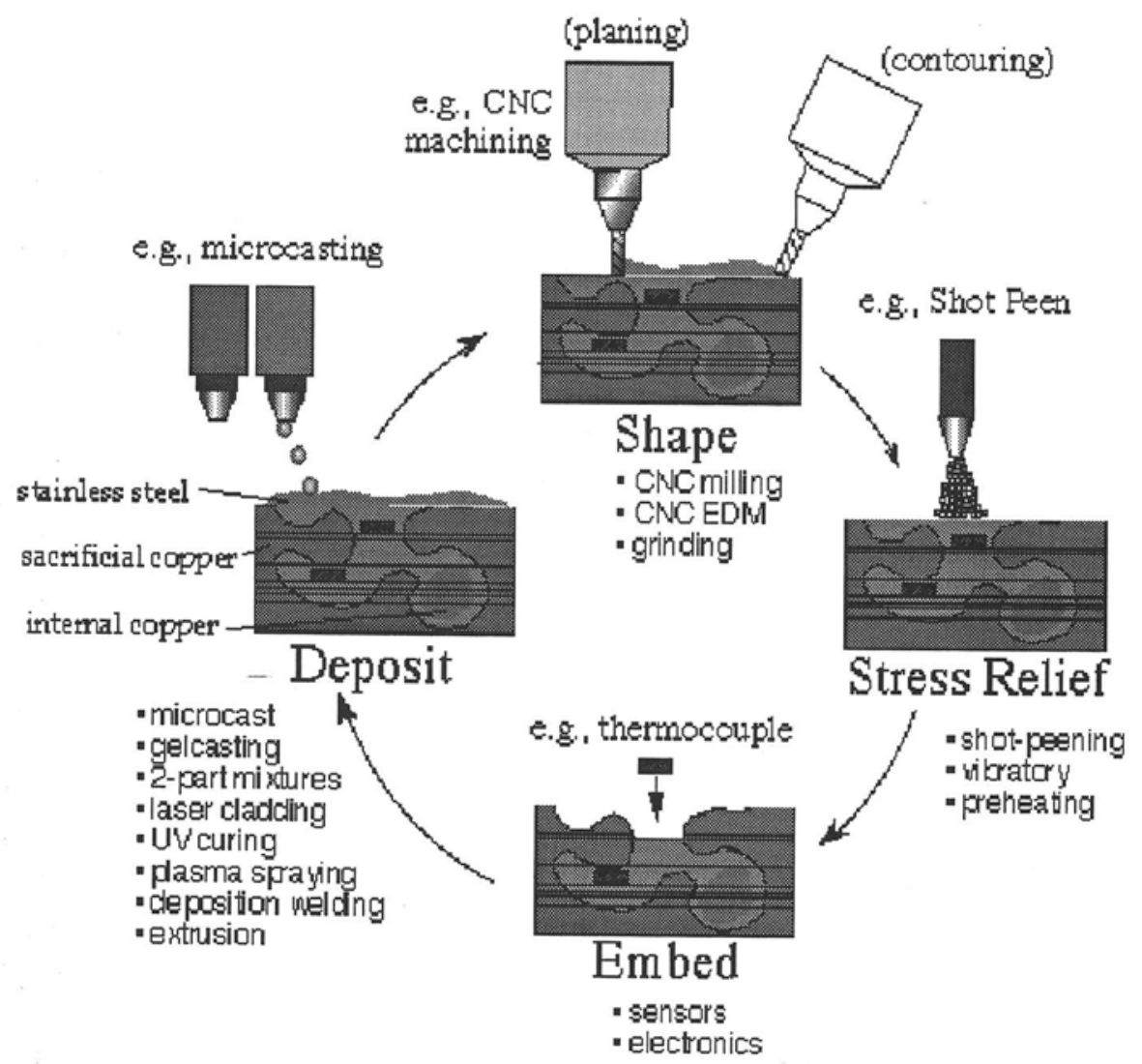

Figure 15: Shape deposition manufacturing. 
The basic SDM strategy is to first decompose a 3D computer-aided design (CAD) model of the structure into simpler building blocks called compacts (Merz, 1994). The compacts are deposited as near-net shapes that are then accurately machined to net-shape before depositing additional material. Sacrificial support material sections are built up simultaneously to provide fixturing for the object. Other intermediate processing operations, such as residual stress-control, inspection, and embedding, can be added to the SDM cycle as required. The SDM process planner decomposes the CAD model into compacts such that:

- each compact is composed of a single material;

- each compact contains the 3D geometric information of outer surfaces and multi-material interfaces; and

- undercut surfaces are not machined, but are formed by previously deposited and shaped compacts.

For example, Figure 16 depicts the sequence for depositing and shaping the compacts, and embedding a component, in a layer of a heterogeneous (i.e., multimaterial, embedded component) structure.

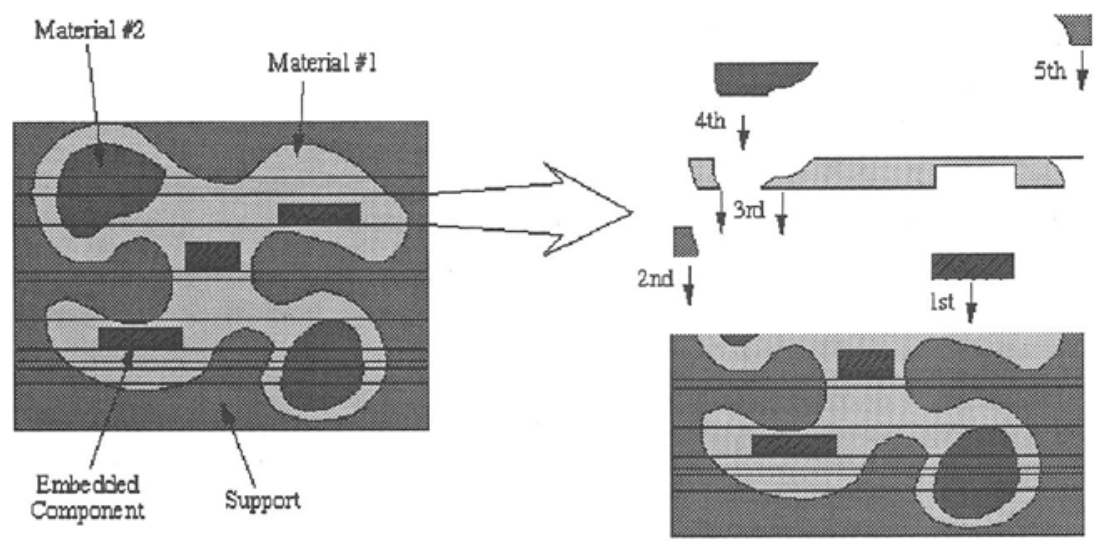

Figure 16: Shape decomposition.

The deposition sources currently available for SDM include micro-casting (deposition of discrete droplets of super-heated molten metal), laser cladding (surface deposition welding of powdered materials), conventional welding (highrate metal deposition), thermal and plasma spraying (spray deposition of molten metals, plastics and ceramics), sputtering (PVD of metals and ceramics), electroplating (metals), gelcasting (deposition and curing of ceramic and metal powders mixed in monomer binders), two-component deposition (dispensing of 
resin/activator mixtures of epoxies or polyurethane's), UV-curing (dispensing and curing of photosensitive polymers) and thermal extrusion (deposition of thermoplastics, waxes or adhesives). CNC machining and electric discharge machining (EDM) are currently available for material removal.

\subsubsection{SDM artefacts}

SDM has the ability to fabricate a variety of novel artefacts. Metals, plastics and ceramics have been used with the SDM process for several different applications. The following sections describe a representative collection of different classes of such artifacts.

\subsubsection{Multi-material structures}

One class of artefacts of increasing importance to industry are structures composed of multiple and functional-gradient materials. Regions of dissimilar materials with different properties can be used to achieve many levels of functional performance, while a continuously varying microstructure can be used for optimisation of part performance. Practical examples for multi-material structures are production tools used for injection moulding (Figure 17) and forming dies for manufacturing composites. Internal copper sections allow fast and uniform heat distribution, and heating/cooling channels which conform to the die cavity can be formed in the interior. In addition, thermocouple sensors for process control can be embedded inside each structure.

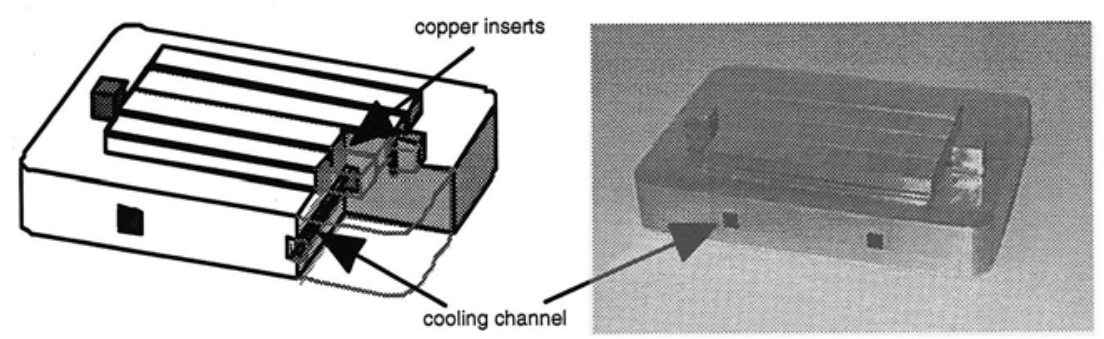

Figure 17: Next generation tool (Fessler et al., 1996). 


\subsubsection{Mechanisms}

The SDM process allows fabrication of "shape-assembled" mechanisms by using sacrificial support material as a buffer between components. During deposition, individual components (e.g., shafts, wheels, axles, sliders) are created simultaneously, divided and held in place by a support material that fills small spaces between them. When the building process is finished, support material is removed allowing individual parts to move freely. Figure 18 shows an example of a simple stainless steel crank/shaft/piston mechanism that was manufactured in one piece with the SDM process.
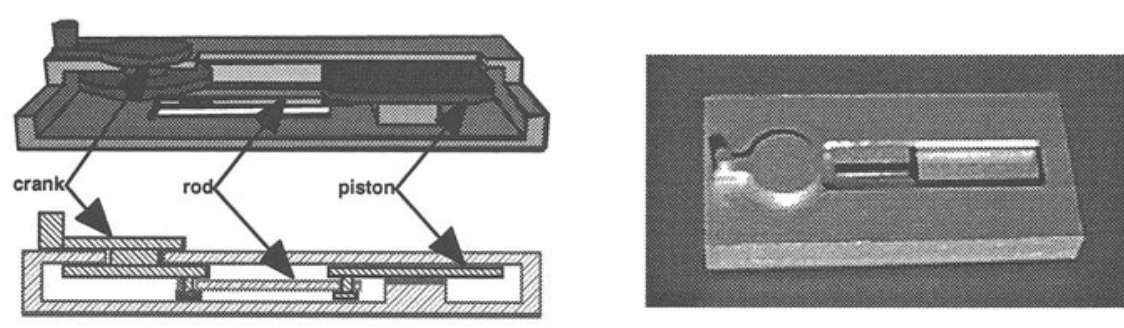

Figure 18: A simple 'shape-assembled' mechanism (Fessler et al., 1996).

\subsubsection{Integrated electro-mechanical structures}

The SDM process is also able to fabricate combined electronic and mechanical structures such as the 'Frogman' underwater, wearable computer shown in Figure 19 (Weiss et. al., 1996). Such embedded electronic assemblies are built-up by depositing layers of two-component poly-urethanes within a sacrificial wax support structure. A 3D circuit is built simultaneously by embedding and interconnecting planar boards throughout the shape. Currently, design and fabrication of such artefacts are done manually, requiring detailed process knowledge and many iterations for simultaneous electronic and mechanical design.

\subsubsection{Mesoscopic devices}

Capabilities of the SDM process have been recently expanded into the mesoscopic size range. Electroplating and micro-CNC machining were used in the Meso-SDM process to create structures and assemblies with dimensions in the millimeter and submillimeter regime. The SEM picture in Figure 20 shows a $5 \mathrm{~mm}$ diameter nickel built assembled on a $1 \mathrm{~mm}$ diameter axle. Clearances between the wheel and the axle are $100 \mathrm{~mm}$. 


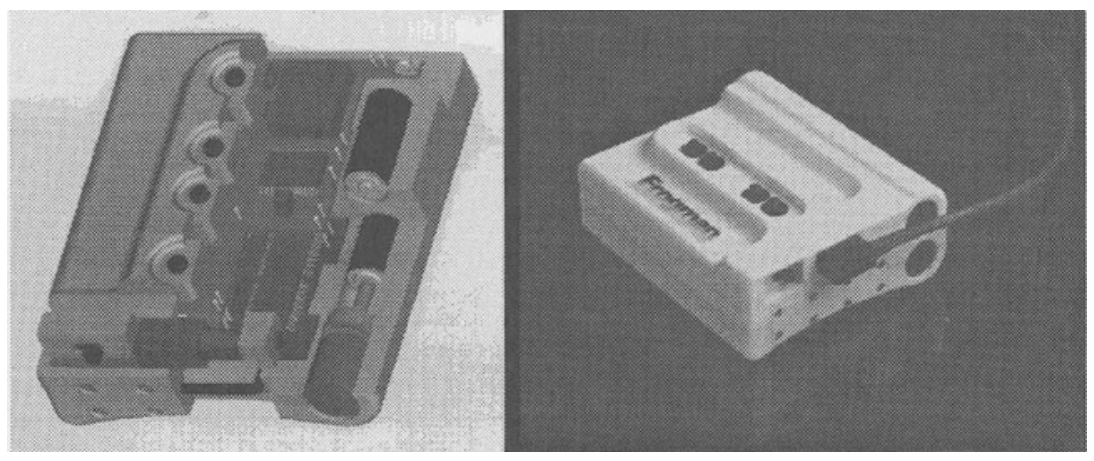

Figure 19: a) CAD model of 'Frogman' b) 'Frogman' built with SDM Embedded electronic assemblies (Weiss et al., 1996).

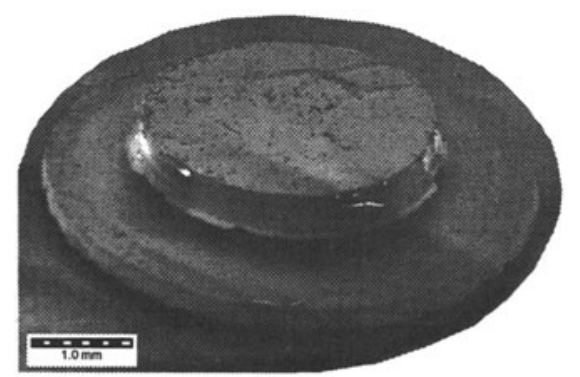

a) Mesoscopic Ni wheel

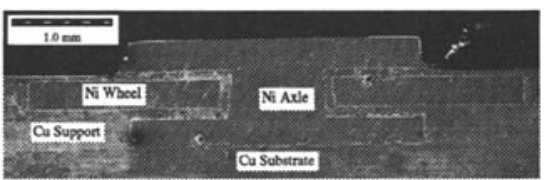

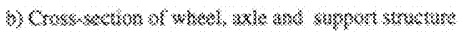

Figure 20: SEM picture of a wheel built by Meso-SDM (Merz and Prinz, 1997).

\subsubsection{SDM fabrication facilities}

SDM has been implemented in test-bed facilities at both the Shape Deposition Laboratory of Carnegie Mellon Univeristy and the Rapid Prototyping Laboratory at Stanford University. To allow for easy addition and exploration of alternative processes, both test-beds currently use flexible robotic automation in which the parts are built on pallets and robotic transport systems transfer the pallets between processing stations. In the future we plan to add material deposition sources directly on our CNC mills to form integrated SDM machines. Upgrading CNC machines with material deposition sources has the potential to give SFF processing capabilities to the enormous world-wide infrastructure of CNC equipment.

In our current test-beds, each station is fully automated to perform the individual material deposition, material removal or intermediate operations. The controllers for each station and the transport system are linked to a central workstation by ethernet or serial (RS-232) connections. For each part, a manufacturing plan is 
calculated by an off-line SDM planning system and downloaded to the central workstation. There, a control program schedules the processing cycle, downloads processing information to the individual stations, and initiates pallet transfers according to the manufacturing plan.

The SDM implementation at the Rapid Prototyping Laboratory at Stanford University (see Figure 21) consists of seven processing stations including 5-axis CNC milling, plasma-based micro-casting, laser deposition (2400W Nd:Yag), low temperature deposition of UV-curable and two-component resins, EDM, a CNC mill with deposition capability for ceramics, and cleaning. Currently the system is capable of producing metal and plastic parts with a $240 \times 240 \mathrm{~mm}$ footprint up to a height of $200 \mathrm{~mm}$. Future plans include adding a 3-axis CNC EDM machine to increase material removal capabilities, a second CNC milling machine with gelcasting deposition heads for ceramic processing and an induction deposition station to facilitate metal droplet deposition through induction heating.

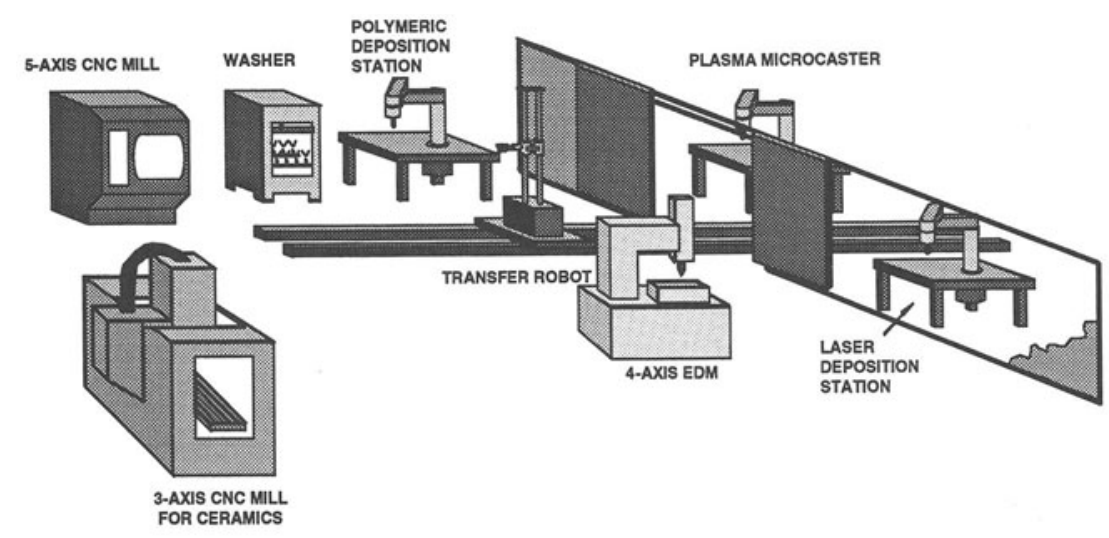

Figure 21: Stanford Rapid Prototyping Laboratory.

Thin-film processing technologies, such as sputtering and photo-lithographic masking, as well as electroplating have been added to the Stanford facility for fabrication of mesoscopic devices and embedding of electronic components and sensors in SDM structures.

The current SDM test-bed facility at Carnegie Mellon University consists of five processing stations including a 5-axis $\mathrm{CNC}$ milling machine, a robotic deposition station, a shot-peener, a cleaner, and a second CNC mill with deposition capabilities for ceramic part fabrication. The robotic deposition station includes conventional welding torches, micro-casters, plasma sprayers, electric arc torches, a low melting point alloy deposition system and a hot-wax dispenser. 


\subsection{Future directions}

Current SDM research efforts are directed towards improving the fabrication process for the type of artefacts described in Section 3, as well as to increase the capabilities for several new classes of novel applications. Improvements in material deposition techniques as well as the introduction of new material removal processes will enhance fabrication, improve the quality of fabricated parts, and allow the creation of layer segments with increased feature complexity and accuracy. The addition of VLSI processing technology will enable the fabrication of smart metal structures by embedding sensors, actuators and possibly electronic circuits directly into high temperature metal material. For Meso-SDM processing material deposition and removal accuracy will be improved to allow smaller feature sizes and better tolerances for mesoscopic device fabrication.

If we imagine that we had SDM facilities in many parts of the world, the notion of faxing the car rather than shipping it could be envisioned.

On the more practical side, the SDM technology expands and changes the design space available to the designer of integrated electronic-mechanical parts. The designer will be able to create multi-material, intelligent parts by controlling the material, mechanical, and electrical properties at both a micro and a macro level without the limitations of traditional manufacturing processes such as machining or casting. By giving the designer control over both the shape and material deposition, this process makes possible the creation of designs that previously were not achievable. Many configurations and structures we currently can't make suddenly become possible.

\section{SYNTHESIS COMPUTER TECHNOLOGIES REQUIRED BY INCREASED DESIGN SPACE}

In order to take advantage of these new possibilities, we need new synthesis methods and tools. New approaches to computer integrated engineering systems capable of reasoning in the unified electronic-mechanical-materials domains are required. Now the creation of possible design alternatives becomes an even more challenging task because of the significantly increased design space.

The following describes some of these emerging computer technologies which either automatically or with user guidance can synthesise structures in two or three dimensions. Conceptual layout is usually one of the first steps in creating a structure. These structures may be in the electrical, mechanical, architectural, or even micro-structural domain. Once laid out, another computer tool capable of detailing completes a full-fledged design. For layout, a tool called ABLOOS is described; for adding design detail the use of a tool called GENESIS is discussed. 


\subsection{ABLOOS: an evolving framework and tool kit for layout design}

Layout design deals with many of the complex issues that typically arise in the design of artefacts that have to satisfy specified constraints and are composed of parts that have shape and take up space.

A large (potentially infinite) number of location and orientation combinations are available for placing any single object. In each combination design objects interact in intricate ways through their shapes, sizes, and the spatial or topological relations that exist between them. These characteristics also interact in complex patterns with multiple performance criteria or functional attributes demanded of the artifact being designed. Layout design decisions must simultaneously satisfy global requirements (e.g. usage of space) and local requirements (e.g. adjacencies between pairs of objects); an acceptable spatial arrangement often exhibits a complex pattern of trade-offs.

For these reasons, there is no known direct method which is guaranteed to produce feasible solutions without trial and error for most application domains. Some amount of exploration of the structure, or formulation, of the layout task and search for candidate for solutions is required. However, due to cognitive limitations, human designers do not have the capability of making systematic explorations of alternative arrangements. This shortcoming in human performance has motivated numerous attempts to apply computational methods to layout. What is desired is a structured method for producing multiple alternatives, each of which embodies trade-offs that can be understood, justified, and indicates a range of possible variations within which optimisation can take place.

Attempts to arrive at such a method confront the challenges mentioned above; consequently there is a long history of attempts to develop an effective computational method reflecting a variety of representations, system architectures, and planning strategies for layout design. Finding an effective representation to support the efficient generation and evaluation of design alternatives has been a difficult undertaking and has dominated the evolution of the field. The representation must support the creation of a space of possible designs by capturing meaningful differences between design alternatives at a manageable level of detail (or abstraction). Layouts for a given design problem are typically very large; therefore, the representation must allow for the employment of effective planning and search strategies to enable reasonable examination of the best alternatives, e.g., through the evaluation of partial solutions and the incremental specification of designs.

In response to the challenges of the layout task and limitations of other approaches, the LOOS system for layout was developed. It enables the systematic generation of layout alternatives and their evaluation over multiple performance criteria. LOOS utilises a particularly promising graph-based representation that separates topological issues (spatial relations between objects) from metrical issues (dimensions and dimensional positions of objects) in layout. The representation 
uses basic spatial relations-above, below, to the right of, to the left--to define the structure or 'topology' of a layout as a set of relations between pairs of rectangles. It represents this structure formally through an arc-coloured directed graph whose vertices represent the rectangles in a layout and whose arcs represent the spatial relations between the rectangles. The following shows an example in which solid arrows indicate above/below relations; dashed arrows indicate left/right relations, and $\mathrm{E}$ represents the minimum enclosing rectangle that is above, right-of, left-of and below all other rectangles in the layout. Using this representation, a set of rules or operations is defined that can generate all possible arrangements of rectangles in a plane by insertion of one rectangle at a time (Figures 22A-B).
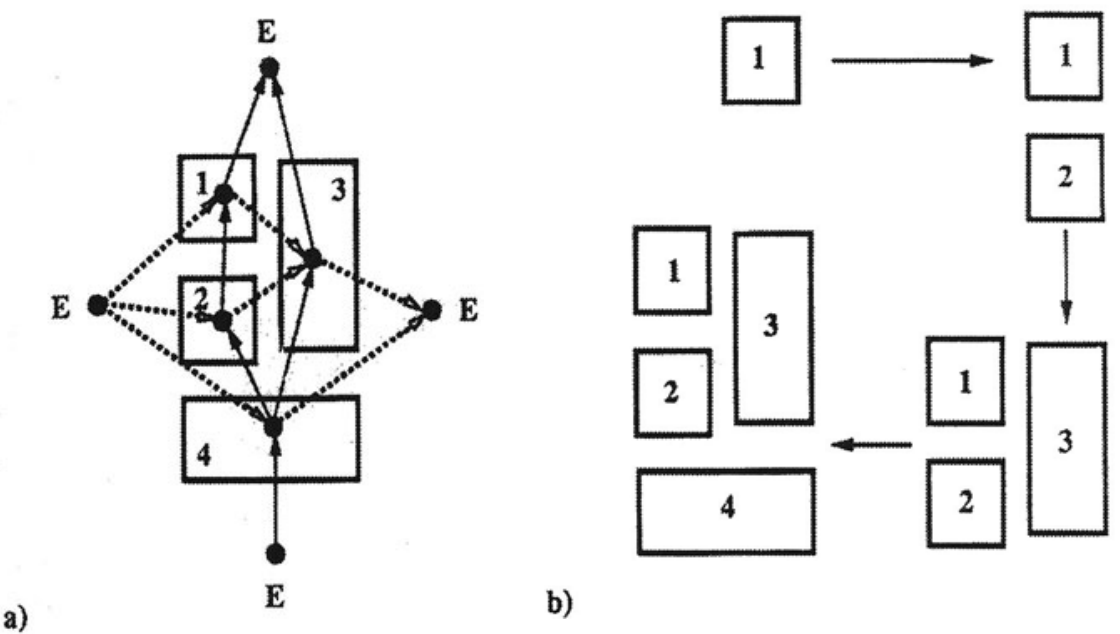

Figure 22: Formal representation and generation of arrangements of rectangles.

The layouts produced by LOOS are loosely-packed arrangements of rectangles; that is, the rectangles are pair-wise non-overlapping, but need not fill a surrounding rectangle. Therefore, the approach is general enough to encompass a broad class of layouts and is useful over a wide range of domains. These rectangular arrangements are given meaning as layouts in a particular domain by attributing the layout objects or components from the domain to respective rectangles. In addition, tests or performance requirements for the layout are attached to these objects, enabling the layouts produced to be comparatively evaluated. Those that are failing requirements may be discarded, while those that 
show promise can be further developed. The general-and-test design strategy of LOOS has enabled it to produce quality solutions for small but realistic layout problems from a variety of design disciplines (Coyne and Flemming, 1990).

ABLOOS (Abstraction-Based LOOS) builds on the LOOS system for layout, increasing the size of the layout tasks it can handle and enhancing its applicability across domains. ABLOOS allows a layout task to be hierarchically decomposed into subtasks using a representation we call goal-objects (GOBs). Each GOB represents a layout problem at a specific level of abstraction. The layout subtasks are then solved and recomposed to achieve an overall solution. (Fig.23 illustrates the architecture of ABLOOS for the first version of the framework) (Flemming et al., 1992).

ABLOOS provides a flexible, hierarchical, and interactive tool kit for layout design. The tool kit is comprised of a collection of operations or rules to generate layouts, propagate dimensional constraints, remove and reinsert objects, aggregate and dis-aggregate objects, and evaluate objects in terms of multiple constraints. The rules work on a formalised, graph-based relational representation. The design process depends on a human computer partnership in which the computer enumerates a space of alternative designs and rapidly evaluates the alternatives. The human-designer creates the evaluation rules and an appropriate decomposition for a given task. The operations in the tool kit may be flexibly combined to yield a variety of powerful methods and strategies for layout design. These range from systematic and exhaustive enumeration of alternatives to incremental interactive design, editing of nearly correct layouts, and redesign.

Applications of ABLOOS have produced high-quality solutions on classes of industrial layout tasks, e.g. the layout of analogous computer boards involving 60 components with multiple constraints on their placement. The adaptability of the framework across domains and disciplines has been demonstrated, and included stacked layouts in $21 / 2 \mathrm{D}$ space and truly 3-dimensional arrangements. The figures on this side (Fig.24) (Flemming et a., 1992) show sample solutions generated by ABLOOS for the layout of an analogous power board. 


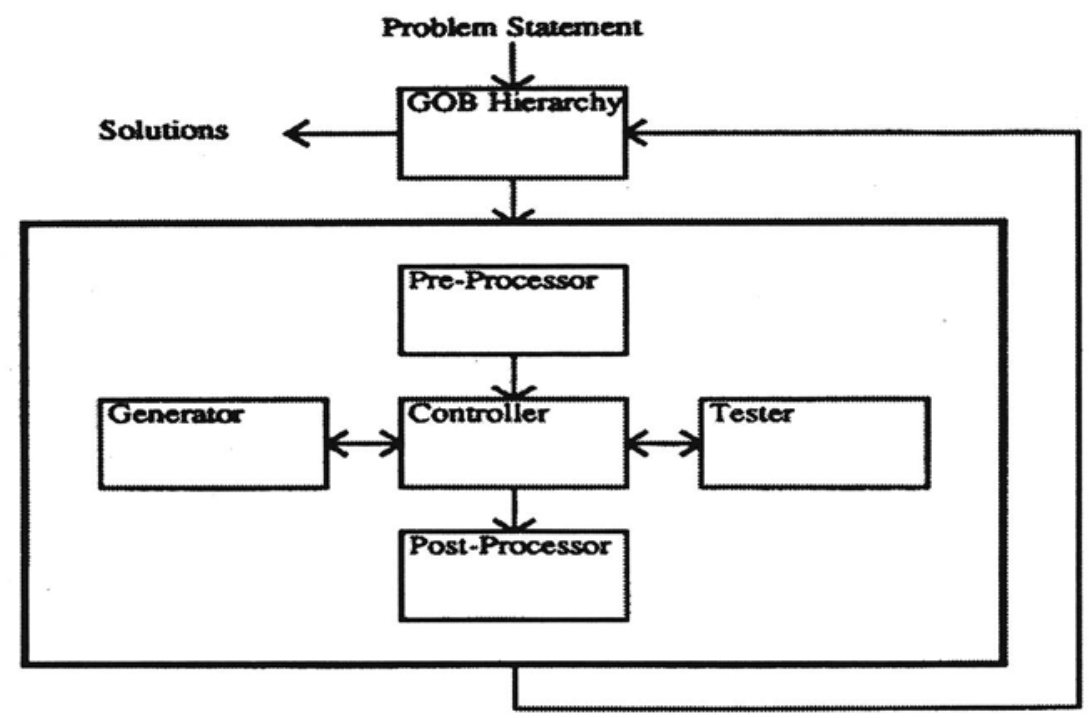

Figure 23: ABLOS architecture - version 1.

Figure 24a shows the final board layout in which all components are placed. Figure $24 \mathrm{~b}$ is the same final placement, but with all interior components of aggregated or hierarchical components shown. Alternative board placement solutions, where the preferred component alignment axis is horizontal, can also be generated using the same decomposition strategy; one of these is shown in Figure $24 \mathrm{c}$.

ABLOOS is currently being extended to handle applications in several domains, including facilities and plant layout computer board and chip layout. Research is underway to incorporate mathematical programming and combinatorial optimisation methods into the framework. ABLOOS is also being used as a test bed to investigate methods of knowledge capture, the building of design repositories, and learning within engineering design environments. 
a)

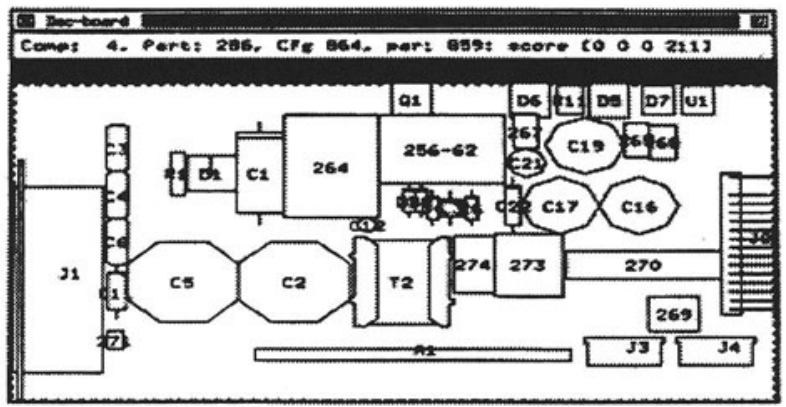

b)

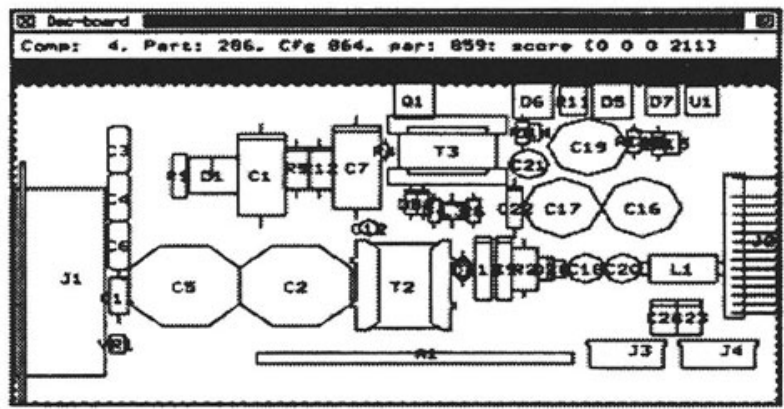

c)

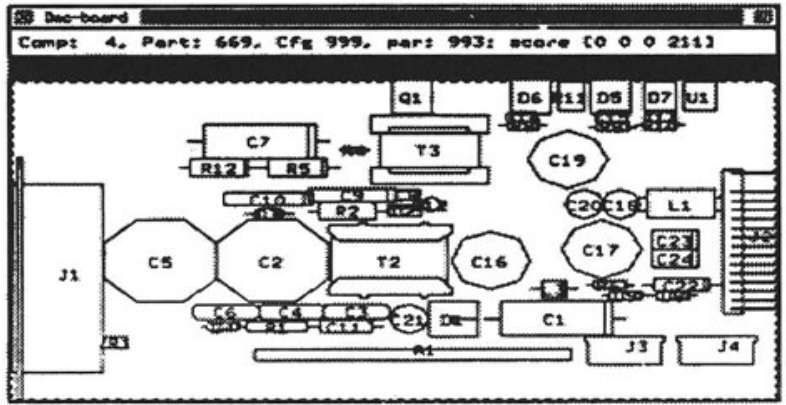

Figure 24: Board placement solutions from top-down power board synthesis.

\subsection{Genesis: a boundary solid grammar}

As mentioned before, laying out abstract objects such as boxes does not make a design. All it does is give a spatially feasible configuration of the objects 
considered. The next step involves incorporating all detailed features of the design, both geometric as well as non-geometric ones. To facilitate this step, it is convenient to introduce a formal language with a grammar to express the intentions of where to generate what entity in what shape and size, and to determine what other non-geometric entity should be assigned to it (Fig.25)

Solids can be represented through their boundaries. The developed boundary solid grammar developed at Carnegie Mellon/EDRC called Genesis provides a means of generating complex models of rigid solid objects. Solids are represented by their boundary elements, i.e. vertices, edges and faces, with co-ordinate geometry associated with the vertices. Labels may be associated with any of these elements. Rules match conditions of a solid or collection of solids and may modify them or create additional solids. A boundary solid grammar uses an initial solid and a set of rules to produce a language of solid models.

\subsection{Integration of information flows and tools}

Integrating and facilitating the top down (synthesis) and bottom up (abstraction) information flow is a key concern in every organisation. In an industrial environment there typically are hundreds, and in some selected engineering domains thousands, of such decision support tools in use to create a single artefact, such as an artefact, such as an aircraft engine. These tools obviously encompass a wide variety of modelling, analysis, and simulation tasks, but need to be properly linked to facilitate top down and bottom up information flows. They are subject to permanent change, and one engineer usually works only with a limited set of such tools. What is important to understand is that the integration of such a large number of decision aids is a discipline in itself. Choosing the proper integration frameworks has an important influence on the productivity, and many would maintain also on the creativity, of an engineering organisation. Creativity increases with the extent that a productive organisation has more time to think.

It is believed that advances in design science in the next ten to fifteen years will increase our understanding of increasingly larger portions of the design process and the design of artefacts. The utility of science-based tools will gradually expand from a few phases of the product creation cycle (detailed design and simulation, detailed design of manufacturing process) to an increasingly larger portion of the total cycle. Most of the tools and methods that have been described here, however, focus only on that detailed design process. 


\section{Boundary Solid Grammars}

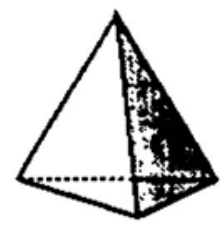

An initial solid,

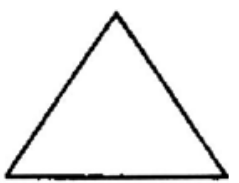

$\Rightarrow$

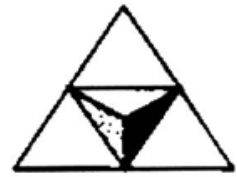

and a solid rule,
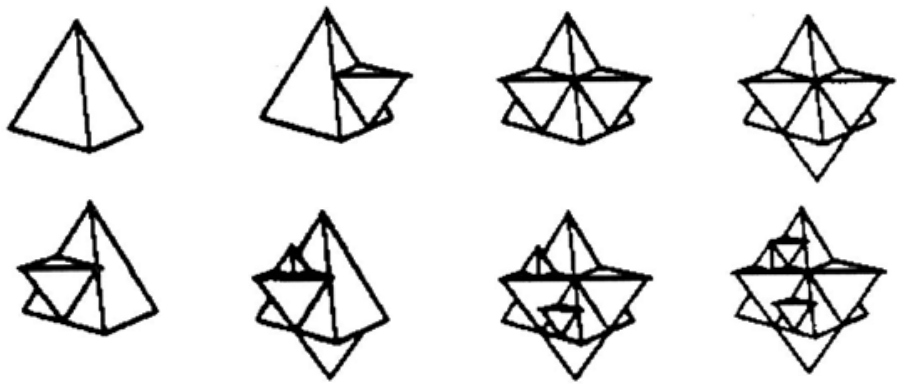

generates a language of solids.

Figure 25: Boundary solid grammars.

Furthermore, tools based on a scientific understanding will evolve from single designer, single-domain "island of automation" through systems which provide a single designer access to tools in diverse domains (e.g. electrical and thermal 
aspects of an artefact). This will culminate in integrated networks supporting multiple design teams.

\section{CONCLUSION}

This article attempted to traverse through various stages of product development and realisation. History shows that the basic manufacturing paradigm for most of our products has not changed. New manufacturing technologies may remove many traditional manufacturing limitations, the consequence of which is a significantly increased design space. The exploration of that new design space will require a new and more powerful synthesis methodologies and tools.

One can be assured that the design research community intends to build an environment in which we can create more freedom for thought, more freedom for the realisation of radically different ideas, and more room for individual and collective brainstorming. This environment creates an atmosphere where the unusual and the unconventional is perceived as normal, and where there is not less, but more time for human interaction and negotiation.

\section{ACKNOWLEDGMENTS}

Portions of this paper were published in 'Management of Design' edited by Sriram Dasu and Charles Eastman, Kluwer Academic Publishers, 1994

The author wishes to acknowledge the input in preparing the section on SPACE DEPOSITION MANUFACTURING by John Fessler, Robert Merz and Lee Weiss of Carnegie Mellon. Lynn Hoschek helped in preparing the manuscript. Financial support from DARPA, ONR, NSF is acknowledged.

\section{REFERENCES}

Charles J. Singer, et al, A History of Technology, eds., Oxford University Press, NY, NY.

Maurice Daumas, (1969), A History of Technology \& Invention, v. 1,2,, ed., Crown Publishers, Inc., NY, NY.

Cooper, Carolyn C., (1988), "A Whole Battalion of Stockers", The Journal of the SIA v. 14, Yale University, New Haven, CT.

Coyne R.F. and U. Flemming, (1990), "Planning in Design Synthesis - Abstractionbased LOOS," Artificial Intelligence in Engineering. Vol. I - Design (Proc. Fifth International Conference, Boston, MA), J. Gero, ed., New York: Springer pp. 91-111. 
Flemming, Ulrich, Can A. Baykan, Robert F. Coyne, Mark S. Fox, (1992), "Hierarchical Generate-and-Test vs. Constraint-Directed Search", Artificial Intelligence in Design '92, John S. Gero, ed., Klumer Academic Publishers, Dordrecht, The Netherlands, 817-861.

Fessler, J. R., Nickel, A. H., Prinz, F. B. and Weiss, L. E., (1996) "Laser Deposition of Metals for Shape Deposition Manufacturing." Proceeding of the Solid Freeform Fabrication Symposium, The University of Texas at Austin, August 10-12.

Hall, Mark A., Atul M. Sudhalkar, Rajit Gadh, E. Levent Gursoz and Friedrich B. Prinz, (1990), "Feature Abstraction in Knowledge-Based Critique of Designs, Issues in Design/Manufacture Integration, A. Sharon (ed.), ASME Winter Annual Meeting, Dallas, TX, DE-V.29: 43-49.

Heisserman, Jeff and Robert Woodbury, "Generating Languages of Solid Models", to appear in the Proceedings of the 2nd ACM/IEEE Symposium of Solid Modeling and Applications, Montreal, May 1993.

Hindle, Brooke and Steven Lubar, (1986), Engines of Change: The American Industrial Revolution, 1790-1860, Smithsonian Institution Press. Blue Ridge Summit, PA.

Merz, R., Prinz, F. B., "Rapid Prototyping of Mesoscopic Devices", Proceedings of the Seventh International Conference on Rapid Prototyping, San Francisco, CA, March/April 1997.

Merz, R., Ramaswami, K., Prinz, F. B., Terk, M. and Weiss, L. E., (1994), "Shape Deposition Manufacturing," Proceedings Solid Freeform Fabrication Symposium, University of Texas at Austin, pp. 1-8.

Merz, R., Shape, (1994), Deposition Manufacturing, Doctoral Dissertation, Department of Electrical Engineering, Technical University of Vienna.

Melvin Kranzberg and Carrol W.Pursell, (1967), "Technology in Western Civilization", V.2,, eds., Oxford University Press, NY, NY.

Weiss, L. E., Merz, R., Prinz, F. B., Neplotnik, G., Padmanabhan, P., Schultz, L. and Ramaswami, K., "Shape Deposition Manufacturing of Heterogeneous Structures", Journal of Manufacturing Systems, Special Issue on Layered Manufacturing, June 1997.

Weiss, L. E., Prinz, F. B., Adams, D. A. and Siewiorek, D. P., (1992) "Thermal Spray Shape Deposition", Journal of Thermal Spray Technology, V. 1 (3), 231-237.

Weiss, L. E., Prinz, F. B., Neplotnik, G., Padmanabhan, P., Schultz, L. and Merz, R., (1996), "Shape Deposition Manufacturing of Wearable Computers," Proceedings of the Solid Freeform Fabrication Symposium, The University of Texas at Austin, August, pp. 10-12. 


\section{BIOGRAPHY}

Dr. Friedrich (Fritz) B. Prinz is the Rodney H. Adams Professor of Engineering at Stanford University. Since 1994 he has held appointments in both the Departments of Mechanical Engineering and Materials Science \& Engineering at Stanford. In addition to his faculty appointments, he is a co-chairperson of Stanford Integrated Manufacturing Association (SIMA). Prinz received his Ph.D degree in physics at the University of Vienna, Austria. In 1977 he was awarded a Fulbright-Hays Visiting Fellowship for research at the Massachusetts Institute of Technology where he also served on the faculty (visiting). Beginning in 1981 he joined the Department of Mechanical Engineering at Carnegie Mellon University and from 1989 through 1994, he held the position as Director of the Engineering Design Research Center at Carnegie Mellon, a National Science Foundation research center. Dr. Prinz's current research activities address a wide range of problems related to intelligent design, rapid prototyping and manufacturing. 